\title{
Carpal tunnel syndrome in women working in tea agriculture
}

\author{
Gul Devrimsel ${ }^{1}$, Serkan Kirbas ${ }^{2}$, Murat Yildirim¹, Aysegul Kucukali Turkyilmaz' ${ }^{1}$, Nilay Sahin ${ }^{3}$ \\ ${ }^{1}$ Department of Physical Medicine and Rehabilitation, Recep Tayyip Erdogan University Faculty of Medicine, Rize, Turkey; \\ 2Department of Neurology, Recep Tayyip Erdogan University Faculty of Medicine, Rize, Turkey; \\ ${ }^{3}$ Department of Physical Medicine and Rehabilitation, Balikesir University Faculty of Medicine, Balikesir, Turkey
}

\begin{abstract}
OBJECTIVE: The aim of this cross-sectional study was to determine the frequency of carpal tunnel syndrome (CTS) among women using tea leaf scissors and compare it with normal population.

METHODS: Two hundred hands of 100 women using tea leaf scissors (tea leaf scissors group) and 112 hands of 56 healthy women (control group) were clinically and electrophysiologically evaluated for CTS. Women using tea leaf scissors were evaluated with visual analog scale (VAS) for pain and Boston Carpal Tunnel Syndrome Questionnaire for symptoms and functional status.
\end{abstract}

RESULTS: Carpal tunnel syndrome was diagnosed bilaterally in $62(62 \%)$ and unilaterally in 7 (7\%) women using tea leaf scissors, whereas $2(3.57 \%)$ bilateral and $6(10.71 \%)$ unilateral cases of CTS was diagnosed in controls. The differences in demographic factors were not statistically significant. In women with CTS using tea leaf scissors, mean symptom severity, functional status, and VAS scores were 2.73 $\pm 0.60,2.42 \pm 0.71$ and $5.19 \pm 1.84$, respectively. There was statistically significant difference in the frequency of CTS between women using tea leaf scissors and the control group and the risk of having CTS among women using tea leaf scissors was approximately 12 times greater $(p<0.001)$.

CONCLUSION: In tea agriculture, working with repetitive flexions and extensions of the wrist highly increases the risk of developing CTS.

Key words: Carpal tunnel syndrome; occupation; using tea leaf scissors.

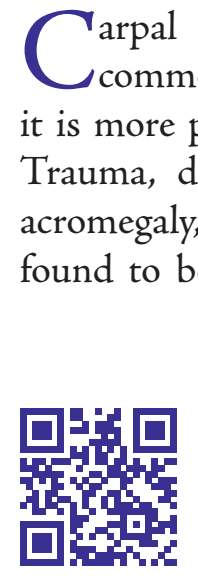

Received: July 22, 2014 Accepted: December 08, 2014 Online: January 24, 2015

Correspondence: Dr. Nilay SAHIN. Balikesir Universitesi Tip Fakultesi, Fiziksel Tip ve Rehabilitasyon Anabilim Dalı, 42001 Balikesir, Turkey.

Tel: +90 266 - 6121010 e-mail: nilaysahin@gmail.com

(c) Copyright 2014 by Istanbul Northern Anatolian Association of Public Hospitals - Available online at www.kuzeyklinikleri.com

were numbness and finger movement dysfunction in both hands [4]. In works that involve repeated forced movements of flexion-extension of the wrist and fingers with inappropriate posture and use of vibrating instruments, the risk of CTS increases [5, $6,7,8]$. The occupations which have increased risk 
for CTS include assembly workers in food industry, especially in meat and fish processing section, garment industry, boot and shoe manufacturing, supermarket cashiers, hand-made carpet manufactory, fishnet and railroad workers [9].

The aim of this cross-sectional study was to determine the frequency of CTS among women using tea leaf scissors and compare it with normal population. To the best of our knowledge the present study was the first to investigate the frequency of CTS among women using tea leaf scissors.

\section{MATERIALS AND METHODS}

Tea leaf scissors are mostly used by women in rural areas of Rize, Turkey. Tea worker women were invited to our polyclinic for physical examination and electrodiagnostic tests. The women (age range 25 to 45 years) were asked to participate in the study investigating the presence of CTS and those who volunteered were included in the study.

One hundred and ninety five women participated in the study. Fifty -four of them having CTS risk factors other than using tea leaf scissors were not included in the study. These risk factors were diabetes mellitus, hypothyroidism, inflammatory rheumatic diseases, renal failure, polyneuropathy, cervical radiculopathy, brachial plexopathy, obesity and wrist trauma. Forty-one women were also excluded from the study because of having occupations with increased CTS risk such as woolen sweater knitters and manual milking besides using tea leaf scissors. The remaining 100 women having no CTS risk factor other than using tea leaf scissors were evaluated by both electrophysiologically and clinically for the risk of CTS. Fifty-six healthy, voluntary women who had no complaints of CTS and none of the risk factors mentioned above for CTS were studied as a control group.

Demographic and clinical features of the subjects were recorded. Employment history and duration of employment were questioned. Because tea working takes 5 months in a year, duration of working was calculated by multiplying months of employment in a year by total number of years. Numbness, tingling and paraesthesia or pain particularly on

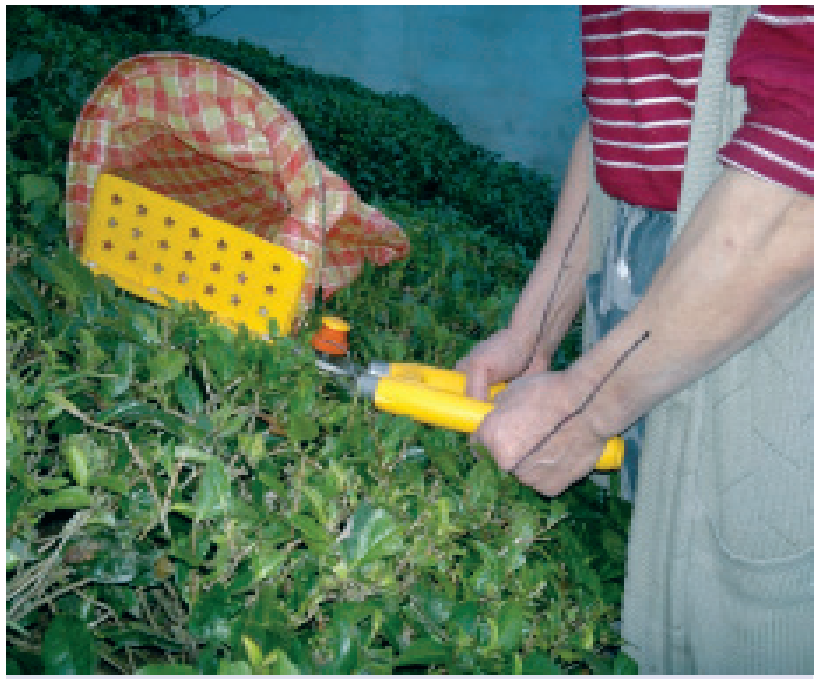

FIGURE 1. Tea leaf scissors is used with elbows in flexion, wrists in extension and strong handgrip with fingers in flexion.

median nerve innervation area, presence of thenar muscle atrophy or weakness, Tinnel or/and Phallen test results were recorded. All patients were asked to point their severity of pain on Visual Analogue Scale (VAS). VAS is a linear scale $10 \mathrm{~cm}$ in length divided in 10 equal parts. Zero indicates no pain, whereas 10 signifies worst pain ever [10]. Patients who were diagnosed as CTS by electromyography also filled Boston questionnaire forms. Boston questionnaire consisted of two parts (symptom severity scale and functional status scale) and includes 11 questions for symptom severity and 8 questions for functional status [11]. Figure 1.

\section{Electrophysiological evaluation}

All participants underwent electrophysiological examinations. Electrophysiological studies (ES) were performed according to the American Association of Electrodiagnostic Medicine guidelines [3, 12]. All electrodiagnostic tests were done with the patient in the supine position, in a room with the temperature kept at $25^{\circ} \mathrm{C}$. All of the studies were performed with a Medtronic Keypoint electromyography instrument (Medtronic Corporation, Minneapolis, MN, USA) in all subjects by the same neurologist. The filter band-pass was $2 \mathrm{~Hz}$ to $3 \mathrm{kHz}$ for motor studies and $20 \mathrm{~Hz}$ to $3 \mathrm{kHz}$ for sensory studies. 
The compound muscle action potential (CMAP) was recorded with surface electrodes placed over the abductor pollicis brevis muscle. Median nerve was stimulated $8 \mathrm{~cm}$ proximal to the anodal electrode by a hand-held stimulator with $2 \mathrm{~cm}$ inter-electrode distance. Duration of stimulus was $0.2 \mathrm{~ms}$, sweep speed was $2 \mathrm{~ms} /$ division and amplitude gain was 5 $\mathrm{mV}$. Measurements were done by a tape measure. Sensory nerve action potentials (SNAP) were obtained orthodromically and recorded by ring electrodes placed at the proximal and distal interphalangeal joints. The distance between the stimulator and recording electrode was $14 \mathrm{~cm}$. Sweep speed was $2 \mathrm{~ms} /$ division and gain was $10 \mu \mathrm{V}$.

An average of ten responses for sensory and five responses for motor evaluation were obtained from each stimulation site. Amplitudes of SNAP and CNAP were measured from peak-to-peak and distal latency from the onset point. Ulnar sensory and motor nerve conductions were also evaluated with the same method. Concentric needle EMG investigations were performed to exclude an additional or alternative disorder. In electrophysiological examination, a distal latency difference of greater than $0.5 \mathrm{msec}$ between median and ulnar sensory nerves were accepted as the hallmark of CTS [9].

\section{Statistical Analysis}

All data in this study were analyzed using SPSS version 18.0 software (Statistical Package for the Social Sciences Inc. Chicago, IL, USA). Descriptive data were reported as means and standard deviations (SD). Student's t-tests were performed to determine the demographic factor differences between

TABLE 1. Clinical findings of women using tea leaf scissors

\begin{tabular}{lcc} 
& Mean & Min.-Max. \\
\hline Age (years) & 38.81 & $25-45$ \\
Working duration (years) & 9.58 & $6-17$ \\
Visual analogue scale score & 5.19 & $3-10$ \\
Boston symptom severity score & 2.73 & $1.72-4$ \\
Boston functional status score & 2.42 & $1-4.62$
\end{tabular}

women using tea leaf scissors and controls. Spearmann's correlation coefficient was used to confirm the correlation between continuous variables. The prevalence ratios of two groups were compared with chi-square test, and odds ratios (OR) with their estimated $95 \%$ confdence intervals (CIs). ES was considered as the gold standard test for CTS diagnosis. Level of significance was set at $\mathrm{p} \leq 0.05$.

All subjects who gave their approval for participation in the study were informed about the study procedure, The study protocol was approved by the local ethics committee.

\section{RESULTS}

After ES, CTS was diagnosed bilaterally in 62 $(62 \%)$ and and unilaterally in $7(7 \%)$ women using tea leaf scissors whereas $2(3.57 \%)$ bilateral and 6 (10.71\%) unilateral cases of CTS were diagnosed in controls. Among these subjects, 20 (20\%) had no complaints, while in women using tea leaf scissors, 67 (67\%) had bilateral and 13 (13\%) unilateral CTS. Seventy- three of 200 hands (36.5\%) were diagnosed as CTS on clinical examination. None of the subjects in the control group had complaints of CTS, while ten hands $(17.85 \%)$ were diagnosed as CTS on physical examination.

Mean age of the participants was $38.81 \pm 0.4$ (range 25 to 45 ) years in women using tea leaf scissors and $38.97 \pm 0.67$ (range 25 to 45 ) years in controls. There were no statistically significant differences as for age and BMI between two groups ( $p>0.05)$. Mean duration of working was $9.58 \pm 5.93$ years. In women with CTS in the tea leaf scissors group, mean symptom severity score was $2.73 \pm 0.60$ points whereas mean functional status score was $2.42 \pm 0.71$ poimts which were evaluated with Boston questionnaire. However, mean VAS score was $5.19 \pm 1.84$ (Table 1). Electrophysiologic study findings and comparison between women using tea leaf scissors and controls are shown in Table 2.

There was a statistically significant difference in the frequency of CTS between women using tea leaf scissors and the control group $(p<0.001)$. The risk of having CTS among women using tea leaf scissors was approximately 12 times greater compared to the 


\begin{tabular}{|c|c|c|c|}
\hline & Women using tea leaf scissors & Controls & P-value \\
\hline mSNCV & $46.06 \pm 10.49$ & $54.89 \pm 7.38$ & $<0.0001$ \\
\hline $\mathrm{mSDL}$ & $3.09 \pm 0.80$ & $2.49 \pm 0.37$ & $<0.0001$ \\
\hline mMNCV & $55.92 \pm 7.26$ & $57.28 \pm 5.37$ & 0.098 \\
\hline $\mathrm{mMDL}$ & $4.31 \pm 1.35$ & $3.31 \pm 0.46$ & $<0.0001$ \\
\hline mSNAP & $22.89 \pm 11.77$ & $29.47 \pm 12.60$ & $<0.0001$ \\
\hline mCMAP & $6.54 \pm 2.35$ & $6.82 \pm 1.63$ & 0.263 \\
\hline D4M-D4U & $0.43 \pm 0.17$ & $0.24 \pm 0.11$ & $<0.0001$ \\
\hline
\end{tabular}

mSNCV: median nerve sensory nerve conduction velocity; mSDL: median nerve sensory distal latency; mMNCV: median nerve motor nerve conduction velocity; mMDL: median nerve sensory distal latency; SNAPa: median nerve sensory nerve action potential amplitude; mCMAPa: median nerve compound muscle action potential amplitude; D4M-D4U: the difference between median and ulnar sensory distal latencies to the fourth digit.

control group (OR:11.77; 95\% CI=5.68-24.39). There were no significant correlations between number of years worked and symptom severity and functional status evaluated by Boston questionnaire ( $r=0.07, p>0.05, r=0.05, p>0.05$, respectively). In addition electrophysiologic study findings did not correlate with the number of years worked ( $p>0.05)$.

\section{DISCUSSION}

Diagnosis of CTS is mainly established with clinical and electrophysiological examinations. Clinically, thenar atrophy, pain and paresthesia along the area innervated by median nerve which increase in severity with repetitive movements and relief of symptoms with changing position of the hand are seen. Tinel and/or Phalen tests are generally positive [13]. In the present study, high VAS and Boston Questionnairre scores indicated that clinical symptoms negatively affected the daily life of women using tea leaf scissors.

In this study we found that the risk of having CTS among women using tea leaf scissors was approximately 12 times greater compared with the controls. Kutluhan et al. [9] reported that CTS was 11.4 times higher in women manually milking cows compared to controls.

It was suggested that prolonged and highly repetitive movements of flexion and/or extension of the wrist increase the risk of CTS, especially when allied with a forceful grip [14]. It was first discovered in 1947 that CTS was related to occupation, when Brian et al. reported approximately 6 cases of work-related CTS in jobs requiring repetitive flexions, and extensions of the wrists [15]. CTS has been listed since 2003 in the European Union's list of occupational disease [16].

In the study by Mondell $\mathrm{M}$ et al. [17] a high occurrence of CTS among floor cleaners was found which was attributed to repetitive movements of the wrists. Barnhart et al. [18] reported CTS in $15.4 \%$ of ski manufacturing workers indulging in repetitive tasks. Kim et al. [19] reported the highest prevalence $(73.9 \%)$ of CTS workers in meat and fish processing plants, and Punnet et al. [20] found a higher prevalence of CTS (\%60) among garment workers. Margolis and Kraus found [21] a prevalence of $62.5 \%$ for symptoms consistent with CTS in female supermarket workers.

The latter prevalence rate is very close to ours (62.5\% versus $69 \%$, respectively). Increased frequency of CTS was also found among dairy workers, vineyard workers and poultry-processing workers however this study was first to investigate prevalence of CTS among women using tea leaf scissors. In tea working, repetitive flexions and extensions of the wrist may increase carpal tunnel 
pressure which may presumably lead to ischemia and direct mechanic injury of the median nerve.

Until today limited number of studies have investigated the relationship between presence of CTS and duration of working. De Krom et al. [22] reported that risks increased 5-to 8-fold when the self-reported time spent in activities with the wrist flexed or extended was $\geq 20 \mathrm{~h} /$ week, while in the study by Nordstrom et al. the risk of CTS doubled for those who work more than $3.5 \mathrm{~h} /$ day among frozen-food packers. Wieslander et al. [23] found that the risk was doubling after one year in a work requiring repetitive flexions and extensions of the wrists. In the present study we could not find a correlation between the duration of working with symptom severity, functional status and electrophysiologic study findings.

In conclusion, in tea agriculture, working with repetitive flexions and extensions of the wrist highly increases the risk of developing CTS. Further studies are needed to confirm these results and evaluate increases in the risk of CTS development with working time.

Conflict of Interest: No conflict of interest was declared by the authors.

Financial Disclosure: The authors declared that this study has received no financial support.

\section{REFERENCES}

1. Phalen GS. The carpal-tunnel syndrome. Clinical evaluation of 598 hands. Clin Orthop Relat Res 1972;83:29-40. CrossRef

2. Phalen GS. The carpal-tunnel syndrome. Seventeen years' experience in diagnosis and treatment of six hundred fifty-four hands. J Bone Joint Surg Am 1966;48:211-28.

3. Croft P. Soft tissue rheumatism. In: Silman AJ, Hochberg MC, editors. Epidemiology of the Rheumatic Diseases Oxford: Oxford University Press; 1993. p. 399-408.

4. Onuma K, Fujimaki H, Kenmoku T, Sukegawa K, Takano S, Uchida K, et al. Bilateral carpal tunnel syndrome due to gouty tophi: conservative and surgical treatment in different hands of the same patient. Mod Rheumatol 2014. [Epub ahead of print]

5. Abbas MA, Afifi AA, Zhang ZW, Kraus JF. Meta-analysis of published studies of work-related carpal tunnel syndrome. DOI:10.1007/s10165-013-0871-6. Int J Occup Environ Health 1998;4:160-7. CrossRef

6. Frost P, Andersen JH, Nielsen VK. Occurrence of carpal tunnel syndrome among slaughterhouse workers. Scand J Work Environ Health 1998;24:285-92. CrossRef

7. Becker J, Nora DB, Gomes I, Stringari FF, Seitensus R, Panosso JS, et al. An evaluation of gender, obesity, age and diabetes mellitus as risk factors for carpal tunnel syndrome. Clin Neurophysiol 2002;113:1429-34. CrossRef

8. Aroori S, Spence RA. Carpal tunnel syndrome. Ulster Med J 2008;77:6-17.

9. Kutluhan S, Tufekci A, Kirbaş S, Erten N, Koyuncuoglu HR, Ozturk M. Manuel milking: A risc factor for carpal tunnel syndrome. Biomedical Research 2009;20:21-4

10. Wewers ME, Lowe NK. A critical review of visual analogue scales in the measurement of clinical phenomena. Res Nurs Health 1990;13:227-36. CrossRef

11. Levine DW, Simmons BP, Koris MJ, Daltroy LH, Hohl GG, Fossel AH, et al. A self-administered questionnaire for the assessment of severity of symptoms and functional status in carpal tunnel syndrome. J Bone Joint Surg Am 1993;75:1585-92.

12. Kummel BM, Zazanis GA. Shoulder pain as the presenting complaint in carpal tunnel syndrome. Clin Orthop Relat Res 1973;92:227-30. CrossRef

13. Simovic D, Weinberg $\mathrm{DH}$. The median nerve terminal latency index in carpal tunnel syndrome: a clinical case selection study. Muscle Nerve 1999;22:573-7. CrossRef

14. Palmer KT, Harris EC, Coggon D. Carpal tunnel syndrome and its relation to occupation: a systematic literature review. Occup Med (Lond) 2007;57:57-66. CrossRef

15. Brain RW, Wright AD, Wilkinson M. Spontaneous compression of both median nerves in the carpal tunnel; six cases treated surgically. Lancet 1947;1:277-82. CrossRef

16. Giersiepen K, Spallek M. Carpal tunnel syndrome as an occupational disease. Dtsch Arztebl Int 2011;108:238-42. CrossRef

17. Mondelli M, Grippo A, Mariani M, Baldasseroni A, Ansuini R, Ballerini $\mathrm{M}$, et al. Carpal tunnel syndrome and ulnar neuropathy at the elbow in floor cleaners. Neurophysiol Clin 2006;36:245-53.

18. Barnhart S, Demers PA, Miller M, Longstreth WT Jr, Rosenstock L. Carpal tunnel syndrome among ski manufacturing workers. Scand J Work Environ Health 1991;17:46-52. CrossRef

19. Kim JY, Kim JI, Son JE, Yun SK. Prevalence of carpal tunnel syndrome in meat and fish processing plants. J Occup Health 2004;46:230-4. CrossRef

20. Punnett L, Robins JM, Wegman DH, Keyserling WM. Soft tissue disorders in the upper limbs of female garment workers. Scand J Work Environ Health 1985;11:417-25. CrossRef

21. Margolis W, Kraus JF. The prevalence of carpal tunnel syndrome symptoms in female supermarket checkers. J Occup Med 1987;29:953-6.

22. de Krom MC, Kester AD, Knipschild PG, Spaans F. Risk factors for carpal tunnel syndrome. Am J Epidemiol 1990;132:1102-10.

23. Wieslander G, Norbäck D, Göthe CJ, Juhlin L. Carpal tunnel syndrome (CTS) and exposure to vibration, repetitive wrist movements, and heavy manual work: a case-referent study. Br J Ind Med 1989;46:43-7. 